\title{
Imprensa jornalística e educação protestante na cidade de Sorocaba no final do século XIX
}

\section{Journalistic press and protestant education in the city of Sorocaba in the late nineteenth century}

\author{
Prensa periodística y educación protestante en la \\ ciudad de Sorocaba a finales del siglo XIX
}

\author{
Ivanilson Bezerra Silva ${ }^{1}$ \\ Wilson Sandano 2
}

DOI: http://dx.doi.org/10.20435/serie-estudos.v23i48.1155

\begin{abstract}
Resumo: O presente artigo tem como objetivo analisar como a imprensa jornalística sorocabana foi utilizada estrategicamente para divulgar a escola protestante em Sorocaba no final do século XIX. Concentramos nossa atenção nos jornais que circularam em 1870-1894, período de maior circulação de notícias relacionadas à inserção do presbiterianismo, implantação da escola protestante em Sorocaba, e também por representar um momento marcado por um acentuado processo de politização, que atribuía à educação a responsabilidade de solidificar os ideais defendidos por republicanos, maçons e protestantes. Entre as escolas que compunham o campo educacional sorocabano, estava a escola protestante organizada pela professora Palmira de Cerqueira Leite. Após a saída da referida professora, assumiu a direção da escola o professor e pastor José Zacharias de Miranda e Silva, que, além de mudar o nome da escola, construiu aproximações com agentes sociais republicanos e maçons, que viam essa instituição educacional como moderna.
\end{abstract}

Palavras-chave: escola protestante; imprensa; maçonaria.

\begin{abstract}
This article aims to analyze how the journalistic press Sorocaba was used strategically to spread the Protestant school in Sorocaba in the late nineteenth century. We focused our attention on the newspapers that circulated in 1870-1894, the period of greater circulation of news related to the insertion of Presbyterianism, the establishment of the Protestant school in Sorocaba, and also because it represented a moment marked by a marked process of politicization, which responsibility to solidify the ideals defended by Republicans, Freemasons and Protestants. Among the schools that comprised the educational field of Sorocaba was the Protestant school organized by Professor Palmira de Cerqueira Leite. After leaving the said teacher, he took over the direction of the school, the teacher and pastor José Zacharias de Miranda e Silva, who in addition to changing the name of the school constructed approximations with social agents republicans and Masons, who saw this educational institution as modern.
\end{abstract}

\footnotetext{
${ }^{1}$ Universidade Brasil, Fernandópolis, São Paulo, Brasil.

${ }^{2}$ Universidade de Sorocaba (Uniso), Sorocaba, São Paulo, Brasil.
} 
Keywords: protestant school; press; freemasonry.

Resumen: El presente artículo tiene como objetivo analizar cómo la prensa periodística serocabana fue utilizada estratégicamente para divulgar la escuela protestante en Sorocaba a finales del siglo XIX. Concentramos nuestra atención en los periódicos que circularon en 1870-1894, período de mayor circulación de noticias relacionadas con la inserción del presbiterianismo, implantación de la escuela protestante en Sorocaba, y también por representar un momento marcado por un acentuado proceso de politización, que atribuía a la educación a la educación, responsabilidad de solidificar los ideales defendidos por republicanos, masones y protestantes. Entre las escuelas que componían el campo educativo serocabano estaba la escuela protestante organizada por la profesora Palmira de Cerqueira Leite. Después de la salida de dicha profesora, asumió la dirección de la escuela, el profesor y pastor José Zacharias de Miranda e Silva, que además de cambiar el nombre de la escuela construyó acercamientos con agentes sociales republicanos y masones, que veían a esa institución educativa como moderna.

Palabras clave: escuela protestante; prensa; masonería.

\section{INTRODUÇÃO}

No final do século XIX, entre o Império e o início da República, a cidade de Sorocaba expandiu intensamente sua atividade educacional, concomitante ao desenvolvimento urbano, início da industrialização e a transição da mão de obra escrava para mão de obra livre. Nesse contexto histórico, a cidade recebeu a inserção de uma nova proposta evangelizadora liderada pelo presbiterianismo. Diante de um momento marcado por transformações e, ideologicamente, diferentes, agentes sociais pertencentes às elites apontaram o rumo que a cidade deveria ter através da política, imprensa e educação. Entre as escolas que compunham o campo educacional sorocabano, estava a escola protestante implantada com o objetivo de atender a lacuna deixada pelo ensino público.

O período representa um momento marcado por um acentuado processo de politização, que atribuía à educação a responsabilidade de solidificar os ideais defendidos por republicanos, maçons e protestantes. Segundo Baddini (2002, p. 11):

A cidade passa a representar o lugar da modernidade, espaço de atuação da sociedade industrial e da cultura burguesa. É sobre essa percepção que se articula o ordenamento do espaço e organização da vida urbana, preceitos básicos do Urbanismo, que emerge como ciência nesse mesmo século, cuja cidade é concebida essencialmente como um lugar passível de intervenção racional = o que induz à submissão da identidade histórica de sua população aos interesses de exploração capitalista. 
A cidade como espaço social precisava, no entendimento da elite sorocabana, passar por um processo de modernização, que seria possível através de novos investimentos políticos, econômicos e educacionais (SILVA, 2010). Sem o devido investimento, segundo os agentes sociais do campo de poder, a sociedade sorocabana permaneceria no caos sustentado até então pelos políticos conservadores, ou seja, dependente economicamente da Feira de Muares, sem modernização do espaço urbano, sem via férrea, sem exploração do algodão, sem a industrialização, sem escolas suficientes, sem uma economia voltada para o progresso, sem a valorização da mão de obra qualificada e outros aspectos.

Pesquisadores locais têm se debruçado na análise do processo de escolarização em Sorocaba no período em tela. Carmo (2006) fez uma análise da relação educação e trabalho no final do Império e na gênese da industrialização em Sorocaba, mostrando que a educação tem papel fundamental e estratégico na estruturação do capital e dos interesses de classes. O trabalho de Gonzalez e Sandano (2004) discute a formação da educação pública em Sorocaba entre 1850-1880, postulando que a escolarização, como campo específico de estudo, representa o espaço da produção da política e da valorização do trabalho como elemento que funda a prática social; dos processos históricos, da racionalidade escolar, das formas privilegiadas de ensino-aprendizagem e de fatores que atuam sobre o cotidiano escolar. Dessotti (2017) mostra, entre outras coisas, que não apenas os grupos elitizados utilizaram a imprensa sorocabana, os operários também a utilizaram como estratégia de luta e reinvindicação dos interesses que tal classe social pleiteava, não apenas no final do século XIX, mas também no início do XX.

É nesse contexto que a imprensa sorocabana é utilizada de forma estratégica e ideológica, com o objetivo de formar um consenso em torno da modernização do espaço urbano. Ela foi utilizada como instrumento de propagação de interesses, valores, princípios, visão de mundo, ideais políticos da elite dominante em Sorocaba. Essa elite era composta de comerciantes, industriais, políticos, intelectuais, jornalistas, quase todos pertencentes à maçonaria sorocabana (SILVA, 2010).

Para a construção do texto, fizemos levantamento dos jornais que circularam na cidade de Sorocaba entre 1869-1899, período de inserção do presbiterianismo e de implantação e existência da escola protestante. Nosso objetivo é analisar como a imprensa jornalística foi utilizada estrategicamente pela elite para disseminar seus ideais, divulgar suas propostas e privilegiar agentes sociais ligados à 
maçonaria, ao presbiterianismo e ao movimento republicano no final do século XIX, na cidade de Sorocaba. Ao expor, numa perspectiva histórica, a contribuição do presbiterianismo norte-americano em Sorocaba, destaca-se sua importância na intermediação do discurso ideológico atribuindo à educação um proposta modernizadora, que vinha ao encontro dos interesses da elite progressista sorocabana do século XIX.

Para tanto, o artigo está estruturado da seguinte maneira: na primeira parte, apresentamos a imprensa sorocabana no final do século XIX, situando-a no contexto de transformações da cidade de Sorocaba e como ela foi utilizada estratégica e ideologicamente; na segunda parte, mostramos a participação dos presbiterianos no campo educacional através dos jornais que circularam em Sorocaba, na segunda metade do século XIX.

\section{A IMPRENSA SOROCABANA NA SEGUNDA METADE DO SÉCULO XIX}

O período de inserção da educação protestante em Sorocaba foi marcado por um forte desenvolvimento da imprensa sorocabana. Segundo DESSOTTI (2017), no contexto da industrialização, a imprensa sorocabana intensificou a propaganda sobre o potencial da cidade para futuros empreendimentos industriais.

Nesse período, foi organizado o jornal O Sorocabano (1870), cujos editores eram Júlio Ribeiro e Pereira Salles. O primeiro converteu-se ao protestantismo e atuou como missionário na cidade de Sorocaba (SILVA, 2010). O jornal trazia vários assuntos relacionados à política local e sobre o presbiterianismo. Nas primeiras publicações, combateu a discriminação idealizada pelos católicos contra o protestantismo. Uma das crises estava relacionada ao enterro de protestantes em cemitérios católicos. Júlio Ribeiro, junto com outros intelectuais, escreveu documentos solicitando à Câmara Municipal um lugar apropriado para enterrar os protestantes. O Sorocabano era vendido ao preço de " 8 \$000 ao anno na cidade e $9 \$ 000$ fora", tinha por princípio "pugnar pelo bem público, com especialidade pelos interesses do município. Dar voz a todas as reclamações justas e comedidas. Reproduzir os clamores da lavoura e do comércio. Abrir espaços a discussões de interesse geral" (O SOROCABANO, 13/02/1870, p. 1). Era seu principal colaborador Ubaldino do Amaral, maçom, abolicionista e republicano. Em 01 de setembro de 1872, transformou-se em O Sorocaba, cujo redator-chefe era Júlio Ribeiro. Outro 
jornal dirigido por ele era A Gazeta Commercial. Chegou a circular diariamente. Apresenta vários artigos que ajudam a compreender como a imprensa enxergava a configuração política, econômica e social de Sorocaba.

Ainda na década de 1870, circulou o jornal O Americano (1871), que tinha seu estabelecimento próximo à Escola Americana. Ele traz severos ataques ao catolicismo e se posiciona a favor da maçonaria. Não se sabe ao certo a ligação desse Jornal com os missionários americanos. O Jornal Ypanema (1872 - 1892), com assinatura no valor de " $8 \$ 000$ por anno em Sorocaba e $9 \$ 000$ fora", foi editado pela primeira vez em 25 de abril de 1872. Publicado "6 vezez por mez", o jornal se propunha a defender os "interesses morais e materiais do município e do Sul da província". E procura "dar na parte litterária alguns bons artigos e vulgarizar os melhores escriptos de auctores nacionais" (YPANEMA, 25/04/1872, p. 1). Seu editor e proprietário foi Manoel Januário de Vasconcellos, maçom, sorocabano de nascimento e coronel da guarda nacional. Participou ativamente da campanha pela instalação da rede de esgoto na cidade. Em 1880, transformado em diário, passou a chamar-se Diário de Sorocaba.

Na década de 1890, surgiram em Sorocaba outros periódicos jornalísticos: A Tribuna (1887) e O industrial (1890). Em 1891 a imprensa sorocabana continuou seu desenvolvimento. Começaram a circular os jornais: A Escola do professor Arthur Gomes, maçom e membro da Loja Perseverança III; O Alfinete, dirigido por João José da Silva, e o 15 de Novembro (1892-1906), editado por João José da Silva. Este último era "Semanário político, noticioso, humorístico e literário", transformou-se em bissemanário e, depois, em 1895, com circulação diária. Sua assinatura anual era de "8\$000 para Sorocaba e $10 \$ 000$ fora" da cidade. O jornal era declaradamente republicano (15/11/1892, p. 1). Em 1893, o proprietário do jornal era secretário da Loja Maçônica Perseverança (15 de Novembro - 19/10/1893). Em 1892, ressurgiu o jornal A Voz do Povo. Na década de 1870, o jornal tinha como editor e redator Domingos Costa. Era publicado duas vezes por semana em dias indeterminados. Circulava com o preço de $9 \$ 000$ por ano e $5 \$ 000$ por semestre. Em 1875, foram publicados 21 jornais entre 04/10/1875 - 10/12/1875, compondo os números 01-16. Os jornais de número 01-15 tinham formato pequeno. A partir do número 16, o jornal tinha uma diagramação maior. Em 1876, circularam na cidade 34 publicações do Jornal - A Voz do Povo, do número 22-55. O número 49, publicado no dia 30/04/1876, foi publicado em cor verde. O mesmo 
aconteceu com o jornal n. 54 (18/05/1896) e o n. 55 (24/05/1876). Embora tivesse cor diferente, não publicou nenhuma matéria relacionada à educação ou notícia relevante relacionada à cidade.

Apenas o número 16, editado em 10/12/1875 (p. 3), publicou uma nota sobre o Colégio União Sorocabano, escola dirigida pela professora Anna Wilke. A nota menciona o exame realizado pelo inspetor de Instrução Dr. J. F. Uchoa Cavalcanti, tendo como examinadores os senhores: Jorge Oetterer, Toledo Pisa, Vicente Eufrásio. Pessoas distintas da sociedade sorocabana. Na primeira página desse mesmo número, é publicado um artigo intitulado: "Os Morpheticos pelas ruas". No período de 1875-1876, o jornal transcrevia textos de Olivério Pillar, Luis Matheus Maylaski, Vicente Eufrásio da Silva e F. de Albuquerque. Os três primeiros eram maçons. Maylaski publicava assuntos referentes à Companhia Sorocabana, balanço anual, proposta de venda, e outros assuntos.

O Jornal A Voz do Povo (1\%/01/1876, p. 3) publicou um pequeno artigo que criticava os americanos. O texto criticava duramente o pensamento norte-americano que se inseria na sociedade sorocabana. Porém o texto não é assinado, parecendo de autoria do próprio editor. O texto é publicado numa página estratégica do jornal. É possível observar que o texto critica a postura consumista norte-americana, que via o trabalho como uma forma de acúmulo de bens materiais, que estava subordinado à educação e à política. Nessa perspectiva, o articulista sugere que as leis são criadas, antes de tudo, para favorecer o trabalho. O articulista critica também a religião norte-americana, afirmando que ela não admitia os prazeres, a refeição não era vista como recreio, e sim a interrupção da diurna tarefa de trabalhar. O texto contrariava a religião norte-americana por não deixar trabalhar aos domingos por coerção religiosa, que prescreve abstenção, sob pena de sacrílego, proíbe o divertimento e até mesmo o fato de receber amigos. Ele afirma: "O americano é mechanico. Mais singular é ainda a descrição, que faz do caracter norte-americano, um próprio cidadão dos Estados-Unidos".

Porém o número 38 (12/03/1876, p. 1) traz um artigo intitulado Trabalho, de Aurora de Silveira, que exalta o trabalho como forma de dignificação do ser humano e do progresso social. Por estar na primeira página do jornal, o artigo parece estar estrategicamente publicado, sugerindo que o trabalho fosse visto como meio de ajudar a sociedade a progredir. Parece contraditório o posicionamento do redator, que critica a visão norte-americana do 
trabalho e que, mais tarde, parecer compartilhar do texto extraído de Aurora de Silveira. O jornal deixou de existir, vindo a circular novamente em dezembro de 1892-1897. Nos levantamentos feitos nos jornais de 03/01/1894-29/12/1895, perfazendo os números 101-335, observamos algumas coisas interessantes. A redação do jornal não está mais sob a responsabilidade Domingos Costa, mas, sob a responsabilidade de Manoel F. de Oliveira. O jornal circula diariamente e, no lado direito do jornal, vem escrito: Estados Unidos do Brasil. $\mathrm{Na}$ primeira página do jornal, o redator afirma que seu estabelecimento fica na rua São Bento, 27. Afirma que os colaboradores do jornal têm plena liberdade de pensamento e não são solidários com a redação. As colunas eram franqueadas para assuntos de interesse público, reclamações de interesse geral, sob responsabilidade dos seus autores. O redator ao dar a localização do lugar em que o jornal é feito parece querer demonstrar a importância do estabelecimento, ou seja, o jornal era publicado numa região central da cidade. A partir do número 125, o jornal passa a ser publicado as quartas, sextas e domingos. Ele diminui o número de circulação, que antes era diário. Até o número 166 publicado em 30/12/1894 não se fala em assuntos educacionais. Apenas o número 167 fala sobre educação.

\section{A EDUCAÇÃO PROTESTANTE NA SEGUNDA METADE DO SÉCULO XIX ATRAVÉS DA IMPRENSA SOROCABANA}

Uma das primeiras aparições da escola protestante, de confissão de fé presbiteriana, na imprensa jornalística, ocorreu no dia 31 de julho de 1870, no jornal O Sorocabano. Nessa nota, o jornal noticiou as atividades da escola noturna mantida pela Loja Perseverança III. A nota traz as seguintes informações:

Matricularam-se desde 07 de setembro passado até 20 de julho d'este anno - alumnos 117, sahiram 65, ficam 52, são freqüentes, termo médio 35. Dos que sahiram a maior parte foi pelos boatos malevolamente espalhados na população de ser a escola protestante; mas hoje, reconhecendo que não ha ali propaganda religiosa de especie alguma, e são admittidas todas as crenças, tem voltado muitos dos que sahiram. Tem se notado grande aproveitamento nos allunos; alguns que entraram sem conhecer o-A-, lêm corretamente manuscriptos e livros, fazem as 4 operações arithmeticas, e exercitam-se em outras contas. A off.'. Perseverança III dá aos alumnos e mestres: livros, papel, Penna, lapis, etc. (O SOROCABANO, 31/07/1870, p. 2) 
Além de mostrar a iniciativa educacional da Loja Maçônica Perseverança III, o texto aponta uma situação vivida no contexto da cidade em relação ao movimento protestante. Afirma que dos 117 alunos, 65 saíram da escola noturna, ou seja, a maior parte, porque se espalhava na cidade um boato de que aquele estabelecimento de ensino era protestante. Pelo que podemos constatar pela imprensa, tratava-se da Escola Americana de confissão de fé presbiteriana, fundada pelo casal Antonio Pedro de Cerqueira Leite e Palmira de Cerqueira Leite. No período da sua organização, atendia as filhas dos agentes sociais que pertenciam à elite sorocabana, inclusive um juiz de direto matriculou suas duas filhas na escola.

No dia 1 o de do corrente mês fundou-se este colégio de meninas, dirigido pela exma. D. Palmira, esposa do sr. Antonio Pedro. Felicitamos hoje de coração ao público, por ter a exma. Sra. D. Palmira, afinal, acedido ao pedido de várias famílias que com ela instavam para por-se à frente de um colégio de meninas. A esmerada educação da diretora, e o grande apoio das mães de família, cremos serem o basta para que ela consolide. O Dr. Juiz de Direito lá tem as suas duas filhinhas e outros cidadãos respeitáveis. Recomendamos aos pais de família, certos de que a educação de suas filhinhas será primorosa, o novo Colégio Palmira [sic]. (YPANEMA, 07/06/1874).

A referida instituição educacional era uma escola particular, criada para o ensino das primeiras letras para meninas. É importante lembrar que as escolas americanas de confissão de fé presbiterianas representavam, desde a sua inserção no Brasil, instituições educacionais modernas que proporcionavam um ambiente de respeito, sentimento de liberdade de consciência, de crítica, noções de ordem, hierarquia, disciplina rígida, exigências éticas, baseadas na combinação de obediência e autogoverno, proibição de castigos físicos, atividades extraclasse: música, clubes literários, ligas de temperança; organização seriada e progressiva (e não, sequencial e linear) dos estudos, conteúdos literários e científicos, trabalho manual como treino para os estudos nos laboratórios, atletismo, educação física, integração entre pensamento e ação, enfim, ideias pedagógicas que foram bem aceitas pelas elites progressistas (HILSDORF, 1977). Embora de origem confessional, elas eram frutos de uma religião que representava progresso para as elites, ou ainda, "ideias mais adiantadas", pois eram ativas, enérgicas, amigas da propaganda e do trabalho (HILSDORF, 1977, p. 152). Para a autora, tais escolas abririam caminho para as atividades de renovação das mentalidades e das práticas dentro dos quadros pedagógicos e, por extensão, da sociedade brasileira. O segundo motivo 
pelo qual essas escolas tiveram a boa aceitação das elites progressistas residia no fato de que tal segmento acreditava que o tipo de ensino ministrado em seus espaços era organizado segundo o sistema norte-americano, que vinha há tempos funcionando como um polo de atração para as elites paulistas, por causa da proposta pedagógica e seu caráter democrático. Ainda segundo a autora, a elite paulista assegurou a maior parte da clientela nas primeiras décadas de organização e proporcionou também adesão dos correligionários, parentes e amigos. Por representar o modelo educacional mais "avançado" para época, logo as elites políticas recorreriam aos educadores norte-americanos em busca de solução para os problemas educacionais do Brasil. Nas palavras de Azevedo (1960), tais escolas representavam o "fermento novo da massa do ensino", por ser o centro de irradiação de atividades renovadas em relação às escolas públicas e privadas.

A escola no período republicano era o emblema da instauração da nova ordem, o sinal da diferença que se pretendia instituir entre um passado de trevas, obscurantismo e opressão, e um futuro luminoso em que o saber e a cidadania se entrelaçariam trazendo o Progresso (CARVALHO, 1989). Nessa linha de pensamento, Warde (2004, p. 2) afirma:

Quatro meses após a Proclamação da República, em março de 1890, teve início a reforma do ensino paulista, marco pelo qual os dirigentes republicanos de São Paulo pretenderam dar visibilidade aos seus lemas e guardar distância do governo central. A presteza com que a reforma foi decretada dá mostras de que as lideranças republicanas que assumiram o governo do Estado de São Paulo estavam de prontidão para começar a república pela educação do povo. Uma educação moderna, guiada por princípios ativos. Pautada no programa de ação elaborado e divulgado por Rangel Pestana nas primeiras páginas do jornal A Província de São Paulo, a reforma de 1890 e seus desdobramentos nos anos subsequentes mostravam claras intenções de fazer das crianças e dos jovens pontos de partida para a gestação de um novo brasileiro, moldado desde o berço por novos comportamentos e habilitado para novas tarefas. Esses traços, ainda que constituídos por meio de referências de variada ordem, dentre as quais se incluíam as europeias e sul-americanas, eram nitidamente constituídos por referência aos Estados Unidos, onde o espírito industrioso se materializava na forma de confiança na ciência e no gosto pelo experimento.

Como representação de um modelo educacional moderno, as escolas americanas chamaram, desde as suas origens no Brasil, a atenção de personagens 
ligados ao partido republicano paulista. Entre os representantes do Partido Republicano, estava Rangel Pestana, figura representativa de importante participação política e que ofereceu o apoio necessário para as escolas americanas de confissão protestante.

Em Sorocaba, a Escola Americana seguiu a mesma linha de aceitação entre as elites progressistas e foi uma das primeiras escolas particulares da cidade. Foi organizada não apenas com o objetivo de atender a lacuna deixada pelo ensino público, mas também para ser um centro de expansão dos valores do presbiterianismo norte-americano e um meio de evangelização indireta (HILSDORF, 1977) ${ }^{3}$. A nova proposta educacional ganhou terreno fértil na cidade devido ao momento histórico. Com a expansão do trabalho missionário norte-americano no Brasil, em 01 de setembro de 1869, os missionários organizaram a Primeira Igreja Presbiteriana de Sorocaba ${ }^{4}$ (BLACKFORD, 1869, p. 1), na casa de José Antonio de Souza Bertholdo ${ }^{5}$, comerciante e maçom. Nessa época, a maçonaria ofereceu o apoio necessário para que os missionários norte-americanos pudessem expandir a nova proposta civilizatória, pois ela coadunava com os interesses políticos de tal instituição. Segundo Goldman (1972), os missionários presbiterianos defendiam o movimento abolicionista e ideias republicanas (LÉONARD, 1981, p. 148).

No relatório de Blackford (1870), documento ${ }^{6}$ enviado à missão norte-americana, encontramos a visão do missionário a respeito do contexto urbano e econômico da cidade de Sorocaba, em que afirma que a cidade de Sorocaba era importante para a proposta defendida pelos missionários norte-americanos. Tinha na época aproximadamente 10 mil habitantes, quase a metade da população da Província de São Paulo. Mas ela, também, destacava-se como centro

\footnotetext{
${ }^{3}$ A autora postula como evangelização indireta a forma pela qual os missionários presbiterianos utilizavam da educação para com fim de evangelização. Tal estratégia estava atrelada aos ideais da Reforma Protestante do século XVI, que defendia ao lado da Igreja uma Escola.

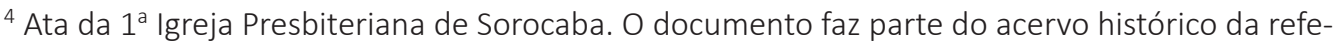
rida Igreja.

5 José Antonio de Souza Bertholdo era membro da Loja Maçônica Perseverança III, organizada em 31 de julho de 1869, por um grupo dissidente da Loja Maçônica Constância.

${ }^{6}$ Carta do Rev. Blackford à missão norte americana (BLACKFORD, 1870, p. 10-2). Carta do Reverendo A. L. Blackford, 20 de setembro. Tradução de Noemi Benevenuto Fontão. Acervo histórico da Igreja Presbiteriana de Sorocaba. Em 1876, Blackford confirma sua visão sobre Sorocaba, dizendo que era um centro natural de um vasto campo (RIBEIRO, 1981).
} 
importante dentro da Capital. Existia, naquela época, a chamada Feira de Muares, que movimentava economicamente a cidade (ALMEIDA, 1951). Blackford destaca duas coisas importantes em Sorocaba: A feira de Muares e o plantio de Algodão.

Segundo Menon (2000), a escola americana estava vinculada à Igreja Presbiteriana de Sorocaba. Constava no seu programa curricular: leitura, caligraphia, arithemetica, systema métrico, grammatica portugueza e geografia (COLOMBO, 06/01/1877, p. 03). Era uma escola que também oferecia francês e música. O Jornal Diário de Sorocaba (26/06/1884, p. 02) tecia elogios, reforçando as novidades pedagógicas da instituição protestante como principal fator do sucesso e elevado números de alunos.

Conforme o relatório semestral da Inspetoria da Instrução Pública do distrito de Sorocaba, escrito pelo inspetor Antonio Gonzaga Seneca de Sá Fleury em 22 de junho de 1883, a escola americana tinha 12 alunos, sendo seis meninos e seis meninas:

Assim uma escola particular mista, de quem é diretor o Ministro Protestante Antonio Pedro de Cerqueira Leite, e professora [...] D. Maria Luiza de Cerqueira Leite $[\mathrm{sic}]$, também protestante, onde leciona, leitura, caligrafia, aritmética, gramática portuguesa e noções gerais de geografia e história Pátria, tendo 12 alunos, sendo 6 do sexo masculino e 6 do feminino, somente nas primeiras letras. (OFÍCIO MANUSCRITO 22/06/1883, ARQUIVO DO ESTADO DE SÃO PAULO, ORDEM 5110).

Para uma escola que começara suas atividades e afirmava ter bastante apoio social, o número de alunos era muito baixo. Porém, no final do ano de 1883, a realidade da escola era outra. Segundo o inspetor, a escola americana tinha 40 alunos, sendo 24 do sexo feminino e 16 do sexo masculino:

D. Palmira Cerqueira Leite - religião Protestante, instalada em 1 o de abril. pp. onde leciona Português, Frances, Inglês, Geografia, história, caligrafia, aritmética e métrica. Existem 40 alunos matriculados e frequentes, sendo 24 do sexo feminino e 16 do masculino. (OFÍCIO MANUSCRITO DE 25/11/1883, ARQUIVO DO ESTADO DE SÃO PAULO, ORDEM 5110).

Segundo o mesmo relatório do Inspetor do distrito, existiam mais 4 escolas particulares, além da Escola Americana:

Existem nesta cidade 5 aulas particulares, das quais 3 são mistas, e 2 do sexo masculino, das quais uma é noturna, e são as seguintes: = sexo masculino = Externato regido pelo cidadão Ignácio de Azevedo Coutinho, instalado 
a 10 de setembro pp. onde leciona 1as. Letras, gramática Portuguesa, aritmética, Frances, e História Pátria, pelo método simultâneo, existindo matriculados 22 alunos: sendo 18 freqüentes. Aula noturna de N. Srä. da Ponte, sustentada por Manuel José da Fonseca, instalada a 25 de Junho pp. e regida pelo Cidadão Germano de Pilar França somente. 1as. letras e para os empregados menores da Fábrica de tecidos de N. Sra. da Ponte, na qual existem matriculados, 26 alunos, sendo todos eles freqüentes. $=$ Mistas $=$ D. Joaquina Genebrina de Oliveira, ensina 1as. letras e prendas domésticas, tendo 24 alunos matriculados e freqüentes, sendo 20 do feminino e 4 do masculino. D. Maria das Dores de Araújo Pavão, somente de 1as. letras, tendo 14 alunos matriculados e freqüentes.: sendo 10 do sexo feminino. e 4 do masculino. (OFÍCIO MANUSCRITO DE 25/11/1883, ARQUIVO DO ESTADO DE SÃO PAULO, ORDEM 5110).

Dentre as escolas particulares mencionadas no relatório, a Escola Americana era a que tinha mais alunos nesse período, dentro do total de 126 alunos matriculados, sendo 72 do sexo masculino e 54 do feminino. A imprensa sorocabana elogia os trabalhos nela realizados:

Nós que vivemos em uma cidade em que se nega todo o auxilio intelectual a imprensa, ao ponto de não encontramos ao menos pessoas que nos forneçam apontamentos e informações, apesar de as instarmos para isso, não podemos deixar de louvar o intento da ilustrada diretora da Escola Americana, que procura implantar no espírito de seus alunos o gosto pelos trabalhos literários. (DIÁRIO DE SOROCABA, 12/10/1884, p. 2).

Porém, na edição posterior do jornal, o pai de uma aluna publica um artigo em que acusava a Palmira de plágio. Numa parte do artigo, ele faz o seguinte comentário sobre a escola:

Illmo. Sr. redator do Diario de Sorocaba. Participo a V.S. que o Sr. Hilário Ribeiro, no seu 4 o livro de leitura, cap. XXV, publicado em Pelotas, reclama a paternidade do elegante trecho histórico filosófico que V.S. publicou na parte editorial de sua folha de 12 do corrente, o qual escrito decerto mui inocentemente lhe entregaram como da lavra de uma das alunas do 'Externato Americano'. (DIÁRIO DE SOROCABA, 17/10/1884, p. 3).

Palmira é reconhecida pelo redator como uma ilustrada diretora, que procurava implantar, no espírito de seus alunos, o gosto pelo trabalho literário. 0 suposto pai da aluna acusa-a de plagiar o texto literário publicado no jornal. Ele demonstra possuir capital cultural e intelectual para posicionar-se contra a postura adotada pela Palmira no campo educacional. 
Palmira não se eximiu da disputa e apresenta a seguinte resposta:

Entre os exercícios gramaticais versou um sobre a tipografia. Sendo um assunto interessante, a discípula cingiu-se quase que textualmente às idéias de Hilário Ribeiro, como autoridade superior, de quem aprendera esse fato histórico. De modo que ela apenas colaborou no final do artigo em que expandia-se sobre a tipografia, deixando simplesmente de por as aspas nos lugares necessários. Quem pode escrever o final do artigo de modo a fazer compreender, também tinha certa aptidão para o seu todo, se não se embelezasse pelas teorias de Hilário Riberio. Na mesma biografia de Guttemberg por Hilário Ribeiro encontram-se varias citações de outros autores. Será ele plagiário? É preciso refletir-se que foi um simples exercício escolar e não um artigo elaborado por mestre. Vindo à minha casa um amigo mostrei-lhe o exercício, e ele gostando do assunto levou-o à tipografia e assim foi publicado. Não seria capaz de constranger uma discípula ao disfarce e ao estratagema como me acusa o zeloso articulista. E, apelando para a emoção, acredita ter explicado o fato. Serve-me isto de aviso de que tenho nesta cidade um inimigo gratuito, que parece querer arrancar o pão da boca de seis orfãozinhos. Minha posição de senhora não me permite continuar qualquer discussão impertinente escrevendo apenas este artigo em atenção aos pais de famílias que me têm confiado suas filhas. (DIÁRIO DE SOROCABA, 19/10/1884).

Palmira não se sentiu acuada diante da luta e da polêmica em torno da sua escola. Porém, após apresentar as razões pedagógicas para combater as acusações sobre sua escola, apela para a emoção e para o fato de ser uma mulher viúva ao concluir que esse acontecimento serviu para compreender que tinha um inimigo gratuito, que desejava arrancar o pão da boca dos seus filhos órfãos. Nesse período, ela já era viúva de Antonio Pedro de Cerqueira Leite. Com esse posicionamento, ela sugere que a escola servia também para sustentar sua família. Percebe-se, também, pela imprensa, que toda a publicação referente à Escola Americana, antes da morte de Antonio Pedro, mencionava a professora Palmira à frente da escola. Isto nos fortalece a ideia de que a proposta educacional presbiteriana na cidade de Sorocaba estava sob a responsabilidade da Palmira, e não do seu marido.

Em 1885, circulam na cidade boatos de que a Escola Americana fecharia suas portas. Palmira volta novamente à imprensa sorocabana para se posicionar, afirmando:

Declaração. Consta-me por algumas pessoas de respeito que alguém nesta cidade propala que vou fechar meu Colégio; para que não creiam que isso é verdade faço a seguinte declaração. Continuarei com meu Colégio a despeito 
de inimigos gratuitos, que pela inveja buscam todos os meios de fazer-me mal. Espero na benevolência dos srs. pais de família que como cumpridora de meus deveres me continuarão a confiar seus filhos e filhas. Palmyra Exel. (DIÁRIO DE SOROCABA, 22/09/1885, p. 3).

Nesta ocasião, assinou sua declaração como Palmira Exel. Após a morte de Antonio Pedro, ela se casou com João Exel, membro da Loja Maçônica Constância (LIVRO DE JÓIAS E MENSALIDES, 1850 , p. 20), em cerimônia celebrada pelo Rev. Zacharias de Miranda, no dia 19 de fevereiro de 1885. Segundo dados lançados nesse livro, João Exel era negociante na cidade de Sorocaba. Como ele não aparece na relação de membros da Igreja Presbiteriana de Sorocaba, podemos especular que o seu relacionamento com Palmira foi construído no campo social, espaço em que ela circulava com muita facilidade devido ao capital cultural, intelectual e social de que era portadora. Palmira mostrava entender na sua nota que a afirmação feita sobre o fechamento da sua instituição escolar era efetuada por "inimigos gratuitos e pela inveja dos que buscam todos os meios para fazer o mal".

A Escola Americana manteve esse nome até 1884 (DIÁRIO DE SOROCABA, 1884, n. 767, p. 2). Após a saída de Palmira de Cerqueira Leite, de Sorocaba, a escola ficou sob a responsabilidade do pastor José Zacharias de Miranda. Como diretor, a primeira providência foi trocar o nome da escola americana, que passou a se chamar em 1885 - Colégio Sorocabano (DIÁRIO DE SOROCABA n. 1013, 24/12/1885, p. 4). O colégio oferecia instrução primária e secundária para alunos de ambos os sexos. Segundo Zacharias de Miranda, o seu estabelecimento de ensino tinha vastas acomodações que poderiam ser utilizadas por alunos através de externatos, internato e meio-pensionistas. Ele tinha muitas expectativas em relação ao colégio. O texto sugere que ele desejava criar novas disciplinas, segundo as necessidades intelectuais dos seus alunos. Outro aspecto que a nota sugere é em relação à disposição do próprio diretor em se prontificar em dar mais informações para as pessoas interessadas. O colégio estava localizado na rua das Flores, rua muito disputada pelo comércio local. A preocupação em relação ao local e à confecção de um prospecto do estabelecimento parece sugerir que ele era bem organizado e que seu dirigente tinha uma preocupação em estar num lugar estrategicamente bem situado.

Sorocaba experimenta um forte desenvolvimento educacional devido às novas exigências imprimidas pela industrialização. O campo educacional em 
Sorocaba nesse período é vasto. Os jornais apontam a existência de outras escolas: Escola Alemã, Escola Teuta-brasileira, Colégio Neuberth, Lyceu Municipal, Externato São Luiz, Escola Noturna Perseverança III e a Escola protestante, chamada posteriormente de Colégio Sorocabano (DIÁRIO DE SOROCABA, 1884, p. 2). Apontam, também, a crise que assolava, na visão dos redatores e colunistas, o ensino público. As críticas ao ensino público pareciam evidenciar que a solução para a educação estava no ensino particular. Isto nos leva a pensar que o grupo de republicanos que mantinha sua hegemonia através da imprensa, queria imprimir na sociedade a importância do estabelecimento de ensino particular. Eles faziam várias distinções entre o ensino público e privado. Apontavam o ensino privado como resposta à crise do ensino público. Mas, boa parte desses intelectuais republicanos estava na direção das escolas privadas, direta ou indiretamente.

No Jornal 15 de Novembro publicado em 10/12/1893 ( p. 1-2), há a publicação do exame anual feito no Colégio Sorocabano. O Artigo registra a participação de figuras importantes da sociedade, numa tentativa de mostrar a importância dessa Instituição para o grupo elitizado. A nota publicada no Jornal 15 de Novembro é extensa e utilizada a primeira e segunda página do jornal. Ela mostra os exames realizados no Colégio Sorocabano. O redator do artigo começa elogiando as contribuições que o colégio produziu para a instrução popular e as acomodações do edifício e a visão sobre a infância. Afirma que aquele momento foi prestigiado por muitas pessoas importantes e pais de alunos. É válido observar a distinção que se faz entre as pessoas distintas da sociedade e os pais de alunos. Há uma tentativa explicita em mostrar o prestigio do colégio para a elite sorocabana. Em seguida, o redator considera os exames feitos sobre várias disciplinas. Através dessa visão, é possível observar as disciplinas que compunham o universo acadêmico do colégio: francês, português, geografia, matemática, aritmética e outras. Em relação à disciplina de Português, é possível identificar pelos exames o tipo de literatura que circulava na escola. Nos exames de português são lidos dois poemas: "Meus oitos Annos" - de Casemiro de Abreu, lido pela aluna Mariana Teixeira Machado, e o poema "Quem dá aos pobres empresta a Deus", de Castro Alves, lido pela aluna Jovina Pereira.

Em seguida, o aluno João de Barros lê um discurso muito bem escrito e articulado, que mostra que foi especialmente escrito para aquele momento. Há o uso de um português correto e de muitas palavras difíceis, que dificilmente estaria 
no vocabulário de um aluno. Além da citação de autores que defende os ideais propagados pelo movimento republicano. Em determinado momento afirma:

O estado é o braço de ferro que deita por terra o monstro da ignorância, é o cedro que se atravessa de margem a margem do ribeiro, para que a inteligência passe da mentira para a verdade, da treva para luz. Pois bem, nos queremos enrijecer o nosso braço para lutar contra o monstro da ignorância, queremos luz para a nossa inteligência que ora desabrocha. (JORNAL 15 DE NOVEMBRO, 10/12/1893, p. 1-2)

Ao se apropriar da frase do escritor contemporâneo, que não é citado, o aluno atribui ao estado a responsabilidade de combater a ignorância, para que a inteligência passe da mentira para a verdade, da treva para a luz e afirma que deseja luz para a inteligência que se desabrochava. É interessante que tais palavras fazem parte do universo maçônico, do ideário republicano e religioso. No mesmo Jornal, na Secção livre, o diretor Zacharias publica outra nota a respeito da reabertura das matrículas do colégio.

É interessante observar a estratégia utilizada pelo diretor Zacharias de Miranda. O seu colégio ocupava, no dia 10 de dezembro de 1893, duas páginas principais do jornal 15 de Novembro. A primeira referência é uma visão do redator do Jornal sobre o Colégio. A segunda referência é o próprio diretor que convoca a população para efetuar a matrícula. A forma como estão colocadas as referências revelam a articulação utilizada pelo redator e pelo diretor do colégio. O redator tece profuso comentário sobre a instituição educacional de Zacharias, logo abaixo, na secção livre do Jornal, Zacharias convoca a população para efetuar a matrícula no ano seguinte.

No Jornal 15 de Novembro circulado em 17/12/1893 (p. 2), há mais um texto longo, escrito por Amaro Egydio, membro da Loja Perseverança III, que tecia elogios ao Colégio Sorocabano, ao diretor Zacharias e ao método de ensino, que ele definiu como sendo o método intuitivo.

A parte introdutória do artigo parece justificar um pedido feito para se escrever sobre o Colégio sorocabano, o que é visto claramente no segundo parágrafo, quando afirma: "quero apenas cumprir o meu dever de assistente e convidado, expondo com franqueza e lealdade que me caracterizam a impressão". Egydio diz ser fraco ao tecer comentário sobre o a escola, embora o texto mostre a sua capacidade de expor com clareza seu raciocínio. Seu artigo leva em consideração o lugar da educação no projeto republicano. No terceiro parágrafo, critica 
o antigo regime que descurou a educação popular. Afirma que como brasileiro assumiu parte ativa na grande evolução social, servindo-se de arauto dos ideais liberais e independentes do regime republicano. Na sua visão as instituições de ensino representam a nova bandeira sacrossanta que desfraldará por todos os lugares da nação brasileira a instrução e o trabalho. Esses dois princípios são ideais republicanos.

O projeto republicano local está em plena consonância com outras regiões do Brasil. O estudo feito por Carmem Moraes (2006) sobre o Colégio Culto à Ciência revela que o projeto republicano foi liderado por maçons. Em Sorocaba não é diferente. O professor Amaro Egydio era ligado à Loja Perseverança III. Ele não somente fala enquanto professor, mas também enquanto maçom e republicano.

Em seu artigo Amaro Egydio afirma que a difusão do ensino é uma cruzada ou guerra santa contra a ignorância e um instrumento para formar o caráter do ser humano. O referido professor vê as crianças como fracas e delicadas, atribuindo à educação a responsabilidade de fortalecer seus espíritos e caráter. Afirma que o Colégio Sorocabano é uma casa de educação e instrução capaz de rivalizar com todas as escolas no Brasil. Em seguida, faz elogios ao diretor do Colégio, afirmando que Zacharias de Miranda é um homem de reconhecida competência, inteligência esclarecidíssima, espírito profundamente cientifico, um bom cidadão, um pai exemplar e dedicadíssimo mestre. Segundo suas palavras, o diretor da escola é um dos poucos ensinadores, que tem perfeito conhecimento da ciência pedagógica. Seu laureado nome é a síntese do ensino público em Sorocaba.

Após se referir à pessoa do diretor como exímio educador, o professor Amaro Egydio faz uma síntese dos exames que aconteceram no colégio, sempre exaltando as posturas dos alunos e a competência do colégio. Tece comentários sobre as instalações, condições do prédio e higiene. Na parte final do seu artigo, afirma que o método pedagógico utilizado no colégio era o método intuitivo, que, segundo sua perspectiva, é apoiado e recomendado pelos grandes mestres, sendo abrigo para o desenvolvimento das faculdades intelectuais e psíquicas. Encerra seu artigo afirmando que o Colégio Sorocabano está destinado a ser um templo onde a pátria é a deusa, e a religião, o futuro.

É válido frisar as aproximações que os presbiterianos fizeram com a maçonaria sorocabana. Zacharias de Miranda circula na região central da cidade e tem livre acesso à imprensa jornalística apoiada pela maçonaria sorocabana. Os 
principais jornais que circularam no período observado, eram de propriedade de maçons republicanos.

O Colégio Sorocabano, segundo a imprensa jornalística, oferecia educação para alunos de ambos os sexos, internato, externato e meio-pensionista. A estrutura da escola, tanto do ponto de vista do redator do Jornal bem como na visão de Zacharias, possuía acomodações amplas, que eram suficientes para atender a demanda. As salas eram espaçosas, e o prédio era muito bem situado. O redator do jornal defende os interesses do grupo maçônico que reivindicava a instalação do novo Grupo Escolar em Sorocaba, o que não podia ser diferente, pois ele era membro da Loja Perseverança III, seu posicionamento no jornal é ideologicamente estruturado com o objetivo de ver concretizados os interesses do grupo maçônico. Apesar de todo esforço através da imprensa, o Governo afirmou que o prédio não tinha condições para abrigar a referida escola.

Por outro lado, pode-se pensar que o projeto educacional de Zacharias de Miranda é muito mais um projeto republicano do que eclesiástico. Não há referência alguma nas atas da Igreja Presbiteriana de Sorocaba sobre o Colégio Sorocabano. Sua articulação acontece mais no âmbito político, embora recebesse sustento da Igreja norte-americana. Isto nos leva a pensar que a Igreja local não tinha envolvimento com o Colégio. Após a transferência dele a São Paulo, seu sucessor não dá continuidade ao projeto. Percebe-se que mantinha relacionamentos com várias Instituições em Sorocaba: maçonaria, jornal, partido republicano, câmara municipal e outros, sem. contudo, envolver a Igreja em seu ideário.

Além de diretor, Zacharias de Miranda atua como político. No Jornal 15 de Novembro circulado entre 10/05/1894 - 28/04/1895 (números 81-175), há várias referências da sua atuação no campo político. O período é marcado pelas eleições municipais. Nos primeiros números, a cidade se prepara para a eleição. O editor publica um artigo sobre o eleitorado sorocabano (23/05/1894). No jornal circulado em 07/06/1894, ele é eleito vereador de Sorocaba com 271 votos. Em 05/07/1894, publica-se a posse dos vereadores eleitos. A partir dessa fase, o jornal publica os atos da Câmara Municipal. A Escola protestante não é mencionada. Seu nome circula como vereador e capitão da cidade. Seu cargo como pastor não é noticiado pela imprensa, apenas os cargos que ocupa na vida pública.

No Jornal 15 de Novembro de (07/03/1895), Zacharias se torna presidente da Câmara Municipal. Como vereador, esteve diante de várias questões relacionadas 
à vida política de Sorocaba: instalação de empresa que seria responsável pela luz elétrica, rede de esgoto, telefonia, impostos sobre serviços prestados e outros.

Pelos nossos estudos (SILVA, 2010), é possível compreender que o protestantismo, ao inserir em Sorocaba num contexto de transformação política (luta partidária entre republicanos e monárquicos), legitima os interesses dos republicanos, assumindo assim uma postura partidária, com a finalidade de alcançar a convalidação da sua proposta religiosa, que contrariava os interesses da religião oficial e da política monárquica.

Em Sorocaba, o protestantismo não somente disputou o campo religioso, mas também o educacional e, para tanto, posicionou-se politicamente (campo político) optando por legitimar os ideais republicanos. Isto é perceptível pela participação do Rev. Zacharias de Miranda na política sorocabana. Em 13 de maio de 1887, aparece entre os eleitos da diretoria do partido republicano (ALEIXO IRMÃO, 1999, p. 390). Com ele, aparecem mais dois presbiterianos, líderes da Igreja Presbiteriana de Sorocaba: João Carlos de Campos e Francisco Rodrigues Pacheco. Em 18 de maio de 1886, na mesma casa que começou a Igreja Presbiteriana de Sorocaba, houve uma reunião do Partido Republicano (ALEIXO IRMÃO, 1999, p. 322). Nessa circunstância, José Antonio de Souza Bertholdo já era falecido. Sua esposa recepcionou os correligionários do partido publicano.

Aleixo destaca a presença de Zacharias de Miranda na política sorocabana em 1888. Os jornais da cidade fazem intensa propaganda do movimento abolicionista. Sorocaba é um das primeiras cidades que começa a libertar seus escravos (ALEIXO IRMÃO, 1999). Em 11 de maio de 1888, em sua casa, realiza o casamento de dois ex-escravos ${ }^{7}$. A atividade política de Zacharias de Miranda é intensa, porém é mais fecunda entre os anos de 1894-1895. Concomitante à sua atividade política, teve uma intensa atividade pastoral e educacional. Mesmo nesse período manteve sua escola, lugar em que atendia alunos de ambos os sexos.

A expansão da imprensa jornalística em Sorocaba nos ajuda a entender como o período em transição do Império para República foi um período marcado por debates políticos e por um acentuado processo de politização e modernização da cidade. A imprensa sorocabana procurou mostrar, em suas páginas, os vários posicionamentos da elite sorocabana sobre aquele momento. Observa-se que

\footnotetext{
${ }^{7}$ Livro de Casamentos da Igreja Presbiteriana de Sorocaba, registro feito por Zacharias de Miranda.
} 
a maioria dos jornais tinha, como proprietário, pessoas ligadas ao movimento republicano e à maçonaria. Entre os jornais, que, de certa forma, faziam uma contra hegemonia por parte do povo, estava o jornal A Voz do Povo, que era muito combatido pela elite emergente.

Por outro lado, esses jornais apresentam farto material sobre as escolas que configuravam o campo educacional sorocabano, inclusive o diretor do Colégio Sorocabano, escola protestante, utiliza-se de vários jornais, principalmente, os ligados à maçonaria para divulgar assuntos relacionados a sua Escola. Outros assuntos fazem parte do cotidiano noticioso da imprensa sorocabana.

O período estudado representa um momento histórico na cidade em que se destaca não apenas o crescimento do processo de escolarização, mas também, a produção literária divulgada na imprensa local, a tensão política entre republicanos e monarquistas, o desenvolvimento econômico da cidade proporcionado pelo processo de industrialização, a reconfiguração do espaço urbano, a demanda pela profissionalização, a demanda pela escolarização, os conflitos religiosos, a participação da maçonaria sorocabana no processo de abolição dos escravos e na divulgação da ideologia republicana através da imprensa, do Clube Emancipatório e Republicano, a inserção de um novo modelo de cristianismo defendido pelo protestantismo.

\section{CONSIDERAÇÕES FINAIS}

A Escola protestante, dirigida inicialmente pela professora Palmira Cerqueira Leite e mais tarde pelo Rev. Zacharias de Miranda, era uma escola particular frequentada pela elite sorocabana. Com o passar dos anos, houve a necessidade de mudar o nome da Escola para Colégio Sorocabano, com o objetivo de torná-la uma instituição educacional mais identificável com a cidade e com os ideais educacionais defendidos pelos republicanos naquele contexto histórico.

Para tanto, foram necessárias várias estratégias para garantir o lugar da escola protestante no campo educacional da cidade, tais como: uso da imprensa como estratégia de divulgação da escola, envolvimento do diretor com a maçonaria sorocabana e por último o seu envolvimento com o Partido Republicano. As relações de poder mantidas pela liderança protestante em Sorocaba com outras instituições explicam que havia um capital cultural e econômico comum entre estas instituições, que garantiram a aproximação, a legitimação, a luta e a concretização de um novo modelo de sociedade, fulcrada no liberalismo. 
Os jornais circulados no período de existência da escola protestante em Sorocaba nos ajudam a compreender não somente o que se ensinava, para quem se ensinava, a partir de que lugar se ensinava. Essas fontes nos ajudam a entender também os aspectos relacionados ao prédio, localização, acomodações e a divisão das classes. Eles também nos ajudam a perceber o interesse em tornar a escola protestante uma das principais escolas em Sorocaba. O diretor da Escola protestante mantinha uma rede de relacionamentos sociais. O seu envolvimento com vários redatores dos jornais permitiu que fizesse uso da imprensa para divulgar seu projeto educacional. Percebeu-se, em vários jornais, que os articulistas externavam sua opinião a respeito desse estabelecimento educacional. As estratégias do diretor da escola foram as mais variadas: relacionamentos através da maçonaria com pessoas ligadas à imprensa e que estavam diretamente ligados ao movimento político da cidade. Nesse período, a imprensa jornalística tinha uma acentuada posição política.

Dois dos jornais que circularam no período estudado, pertenceram a Júlio Ribeiro, que estava ligado ao movimento protestante, maçônico e político da cidade. Através desses jornais, muitos assuntos relacionados ao protestantismo foram divulgados com a finalidade de referendar os ideais postulados por tal movimento. Percebeu-se, também, que o grupo de intelectuais em que Zacharias de Miranda estava inserido, era um grupo envolvido com questões políticas, educacionais, sociais e maçônicas na cidade de Sorocaba. Como diretor da escola, gozava de prestígio entre a elite sorocabana, o que the garantiu um lugar de poder na sua prática escolar, política e pastoral e um lugar privilegiado no espaço social sorocabano.

A inserção do Rev. Zacharias de Miranda na política sorocabana, no final do século XIX, garantiu seu posicionamento no campo educacional. O respaldo oferecido pela liderança política permitiu que a Igreja Presbiteriana de Sorocaba e seus principais líderes pudessem ter um papel decisivo na política, garantindo, dessa forma, não somente a identidade da Igreja, mas também o seu lugar no campo político, educacional e religioso de Sorocaba.

Pode-se dizer que a imprensa jornalística em Sorocaba, no final do século XIX, teve um papel decisivo na construção de um ideal de sociedade defendida por republicanos, que atribuía à educação a responsabilidade por estabelecer a nova ordem social. As escolas, principalmente, as particulares ligadas aos republicanos, 
foram evidenciadas pela imprensa como o instrumento para a concretização dos novos anseios sociais que faziam parte do universo político e ideológico dos seus protagonistas. Nesse sentido, a escola protestante é amplamente divulgada pela imprensa como uma instituição que contribuiu para a construção dessa nova sociedade.

\section{REFERÊNCIAS}

ALEIXO IRMÃO, José. A perseverança III e Sorocaba. Da fundação à Proclamação da República (1869-1899). Sorocaba, SP: Fundação Ubaldino do Amaral, 1999. v. I.

ALMEIDA, Aluiso. História de Sorocaba-1822-1889. Sorocaba, SP: Gráfica Guarani, 1951. AZEVEDO, F. de. Uma interpretação do Instituto Mackenzie. Conferência de Fernando de Azevedo proferida no 90 aniversário do Instituto Mackenzie. O Mackenzie, São Paulo, ano 20, n. 61, dez. 1960.

BADDINI, Cássia Maria. Sorocaba no império: comércio de animais e desenvolvimento urbano. São Paulo: Annablume/Fapesp, 2002.

BLACKFORD, A. L. The Missionary. (Editada por "The Secretary of Foreign Missions of the Presbyterian Church,USA, monthy from Richmond, Virginia). Janeiro, 1870. p. 10-2.

BLACKFORD, A. L. Primeiro Livro de Ata da Igreja Presbiteriana de Sorocaba. Sorocaba, SP, 1869.

CARMO, Jefferson Carriello. Algumas aproximações entre a educação e trabalho em Sorocaba no final do século XIX e no início do século XX. Revista HISTEDBR on-line, Campinas, SP, n. 21, p. 141-52, mar. 2006.

CARVALHO, M. M. C. de. A escola e a república. São Paulo: Brasiliense, 1989.

DESSOTTI, Isabel Cristina Caetano. A educação operária no final do XIX e início do XX em Sorocaba sob o olhar da imprensa: o escrito e o silenciado. 2017. Tese (Doutorado em Educação) - Universidade Estadual de Campinas (UNICAMP), Campinas, SP, 2017.

GONZALEZ, Jorge Luiz Cammarano; SANDANO, Wilson. A formação da educação escolar pública em Sorocaba 1850-1880. Revista HISTEDBR on-line, Campinas, SP, n. 16, p. 3660, dez. 2004.

GOLDMAN, Frank P. Os pioneiros americanos no Brasil (educadores, sacerdotes, covos e reis). São Paulo: Pioneira, 1972.

HILSDORF, Maria Lúcia S. Escolas americanas de confissão protestante na Província de São Paulo, um estudo de suas origens. 1977. Dissertação (Mestrado em Educação) Universidade de São Paulo (USP), São Paulo, 1977. 
LÉONARD, É. G. O protestantismo brasileiro: estudo de eclesiologia e de história social. Rio de Janeiro: JUERP, 1981.

LIVRO de Jóias e Mensalidades da Loja Maçônica Constância, 1850. 54p.

LIVRO de Registro de Casamentos da Igreja Presbiteriana de Sorocaba: 1877-1890.

MENON, Og Natal. A educação escolarizada em Sorocaba entre o Império e a República. São Paulo: PUC, 2000. v. I., 367p.

MORAES, Carmen Sylvia Vidigal. O ideário republicano e a educação. Uma contribuição para a História das Instituições. Campinas, SP: Mercados das Letras, 2006.

OFÍCIO encaminhado ao Inspetor Geral da Instrução Pública, por Antonio Gonzaga Sêneca de Sá Fleury, Inspetor do Distrito da Instrução Pública de Sorocaba, em 25 de novembro de 1883.

RIBEIRO, Boanerges. Protestantismo e cultura brasileira: aspectos culturais da implantação do protestantismo no Brasil. São Paulo: Casa Editora Presbiteriana, 1981. 416p.

SILVA, I. B. da. A cidade, a igreja e a escola: relações de poder entre maçons e presbiterianos em Sorocaba na segunda metade do século XIX. 2010. Dissertação (Mestrado em Educação)- Faculdade de Educação, Universidade de São Paulo (USP), São Paulo, 2010.

WARDE, M. J. O futuro está nas mãos da psicologia e da pedagogia científica: São Paulo, dos anos dez aos anos trinta do século XX. ENCONTRO REGIONAL DE HISTÓRIA - O lugar da História, 17. ANPUH/SPUNICAMP. Anais... Campinas, SP, 6 a 10 de setembro de 2004. Cd-Rom.

\section{JORNAIS:}

15 de Novembro

A Gazeta Comercial

A Tribuna

A voz do Povo

Colombo

Diário de Sorocaba

O Americano

$O$ industrial

O Ypanema 


\section{Sobre os autores:}

Ivanilson Bezerra Silva: Doutorado e Mestrado em Educação pela USP. Graduação em Pedagogia pela Universidade de Sorocaba. Membro do grupo de pesquisa Estudos História da Educação e Religião GEHER (USP), grupo de pesquisa Núcleo Multidisciplinar de Estudos do Protestantismo - NUMEP (Mackenzie) e Intelectuais da Educação Brasileira (USP). Atualmente Diretor Geral da Faculdade de Tietê (Universidade Brasil).E-mail: rev.ibs@gmail.com

Wilson Sandano: Professor titular do Programa de Pós-Graduação em Educação da Universidade de Sorocaba. Pesquisador do Grupo de Estudos de História da Educação. E-mail: wilson.sandano@prof.uniso.br

Recebido em abril de 2018

Aprovado em maio de 2018 